\title{
Institutional promotion of research in Humanities and Social Sciences in Spain: SINC news agency of the Spanish Science and Technology Foundation-FECYT.
}

\begin{abstract}
For a few decades now, the general finding of the decline of "humanistic" areas of knowledge in most countries has been recurrent, while guided teaching and research around disciplines understood as more "scientific"-particularly those grouped in the STEM area and those related to Health and Biomedicine - have become increasingly popular. The widespread perception of the low utility and social application of humanistic knowledge, as well as its lack of scientific rigor, is not only common among citizens but also very prevalent among the research community, especially in the design of institutional policies for the social promotion of knowledge and scientific culture. In this study, we analyze the communicative strategy of research promotion at SINC news agency, as a sample of the institutional policies that are promoted by the Spanish public institutions in relation to the Humanities and Social Sciences areas. To this end, we use a methodological strategy that combines the quantitative and qualitative analysis of the contents understood as "humanistic" published in SINC and compare it with a sample of those perceived as more "scientific." The results of the analysis confirm the low institutional interest in the promotion of "humanistic" knowledge by the SINC news agency of the Spanish Science and Technology Foundation (FECYT).
\end{abstract}

KEYWORDS: scientific culture, science communication, scientific journalism, science, humanities, social sciences, scientific policy, research, universities, institutional communication

\section{Introduction.}

The subsidiary value attributed to Humanities in current societies is argued in relation to the contemporary institutional interest in promoting applied knowledge deriving from research carried out in STEM (Science, Technology, Engineering \& Mathematics). Applied knowledge and research is intensively encouraged, especially since the famous report by Vannevar Bush in the immediate post-war context of World War II (Bush, 1945). In the last decade, the gap that separates "humanities" from the rest of the "sciences" and forms two radically different and confronting cultures has been widening, as Snow denounced in early 1959 (Snow, 2000).

This is despite the multidisciplinary alternative represented by the promotion of an area of research that grouped studies in Science, Technology, and Society (STS), after the presentation of the Club of Rome Report in 1962 on The limits of growth. In STS studies, Humanities and Social Sciences play a central role; nevertheless, they do not stand strong as a multidisciplinary counterpart to the persistent fragmentation of knowledge in different disciplines, which seem increasingly distant from each other. The social consequences of the close interrelation of institutional policies based on the current economic system, (Quintanilla, 2015; Rodríguez-Serrano and Gil-Soldevilla, 2018; Van Dijck, 2003), also known as "MIT ideology," (Morozov, 2013) are being increasingly criticized.

In this sense, various forms of philosophical neopositivism persist in research practices and in the generation and promotion of knowledge, especially in relation to the so-called "sciences." As recent studies demonstrate, for researchers, the communication of knowledge continues to be perceived as a strategy to minimize social resistance to scientific-technical progress (Pestre, 2008) to restore confidence in science among citizens (Besley et al., 2018). Alternatively, knowledge is disseminated in a simple manner to expand and guarantee new financial forms and resources for research that, at present, is generally perceived in relation to 
its "social utility": for example, by promoting new financing strategies such as crowdfunding. (Schäfer et al., 2016).

Contrarily, because of the growing epidemic of falsifications in research, control enhancements by all parties involved in the science system is resulting in the supposed certainty provided by science (Gustafson and Rice, 2019; Landström et al., 2015; xxx, 2019), as opposed to humanities. Such measures are being increasingly questioned.

However, the progressive commercialization of knowledge and the undisguised promotion of neoliberalism in the scientific and political systems of many countries (DavidsonHarden, 2013) - and the increasingly frequent detection of falsifications-does not imply that the individual ideology of the researcher or scientific community is not honest. Evidently, there is a need to approach scientific policies, indeed the very notion of "science", from a much more multidisciplinary perspective, wherein Humanities and Social Sciences have much more to contribute.

\section{The decline of Humanities and Social Sciences.}

The historical roots of the progressive decline of humanistic knowledge since the beginning of the industrial revolution have been examined in previous studies (RiveroFranyutti, 2013), especially in relation to the extensive imposition of empirical research methods by the Baconian proposals and the controversial particularity of a polysemic term combining the humanistic areas of knowledge (Olmos-Peña et al., 2015). Likewise, the incoherence and fragmentation of research in the humanistic areas have been vehemently criticized. This is not limited to the supposed intellectual imposture on which some works are based and their little or no scientific validity (Sokal and Bricmont, 1999). More recently, and in a controversial way, the growing orientation of research towards the political activism in diverse sectors has also been criticized, especially regarding Humanities and Social Sciences in the "publications of the complaint" by the Grievance Studies Project (Lindsay et al., 2018).

Nevertheless, beyond these frontal attacks, and certainly not without reason, the common perception of a lack of "scientificity" in the areas of knowledge integrated especially by Humanities and their low social value seems widespread (Knudsen, 2017). Recent specific studies on the value granted by the citizens to the Social Sciences show the generalized perception of their limited usefulness as part of the journalistic discourse (Huber et al., 2019). Even in countries like Japan, Humanities and Social Sciences are being eliminated from university studies (Grove, 2015), even though our academic environment has not reached that far and the historical claims promoted in these areas of study from European institutions have persisted (Griffin, 2007).

However, recent reports in this regard are disappointing (Bueno et al., 2019). The specificity of humanities in the difference among research methods and practices, and their discursive character with respect to the considered sciences, continues to be highlighted, without implying that their results are not valid or socially useful. It is common to continue classifying studies in the area, especially Humanities and Social Sciences, as unscientific and of little value or social utility than other sciences. This is particularly true in relation to studies integrated into the STEM group, and those related to the areas of Biomedicine and Health Sciences.

To add to the difficulties, the social impact of Humanities and Social Sciences is difficult to determine, since its benefits are not usually immediate. Additionally, humanistic knowledge is not found in specific sections of the media - unlike scientific knowledge, which is easily identifiable - making it very difficult to determine its presence in the public space and social discourse. Furthermore, research in this regard is very scarce. The only two research 
works that have been conducted on the presence of Humanities and Social Sciences in the media, based on the pioneering meta-analysis (Schäfer, 2012), present very disparate data that vary from figures indicating a presence of less than $30 \%$ to more than $60 \%$ of humanistic disciplines, depending on the criterion adopted (Šuljok and Vuković, 2013; Summ and Volpers, 2016; Vestergård and Nielsen, 2016). In a macro-study conducted more than a decade ago on a group of 13 countries (Bentley and Kyvik, 2011), excluding Spain, all knowledge areas were considered. The results indicated that scientists from Hong Kong disseminated research activity the most, followed by those from Germany. The data showed a significantly greater presence and generalized dissemination productivity in researchers in humanities compared with those in science. However, the difficulty in identifying these areas is so high that in another recent automated macro-study on scientific news in the Spanish press, analyses related to Humanities and Social Sciences were consciously excluded, strictly limiting it to the analysis of "pure sciences, biology and medicine" (Groves et al., 2016: 693).

Given the difficulties in delimiting the specific humanistic contents that appear in the media - and with the aim of contributing to the determination of the social value of Humanities and Social Sciences - in this study, we analyze the dissemination of research results in these areas from an institutional perspective - that is, from the public administration. To this end, we analyzed the contents distributed by the SINC news agency, part of the Spanish Foundation for Science and Technology (Fundación Española para la Ciencia y la Tecnología - FECYT), which, until recently, depended on the Ministry of Science, Innovation and Universities in Spain. ${ }^{l}$

\section{Delimitation of the object of study and working hypothesis.}

This work originated from an evident contradiction that was found after we conducted a brief analysis of some of the institutional instruments that the Spanish administration created (in the last decade) to promote the generation of knowledge, evaluate the productivity of the research community, and promote scientific culture among its citizens.

A quick analysis of the first of them, the "six-years terms of research" of the group of PDIs of the Universities (Ministry of Education. General Secretariat of Universities, 2019), clearly shows significant differences in research productivity by areas of knowledge (Figure 1).

\footnotetext{
${ }^{1}$ At the time of writing, in January 2020, and as a result of the ministerial restructuring after the formation of the new government, this ministry has been divided into two, one for Science and Innovation and the other for Universities.
} 


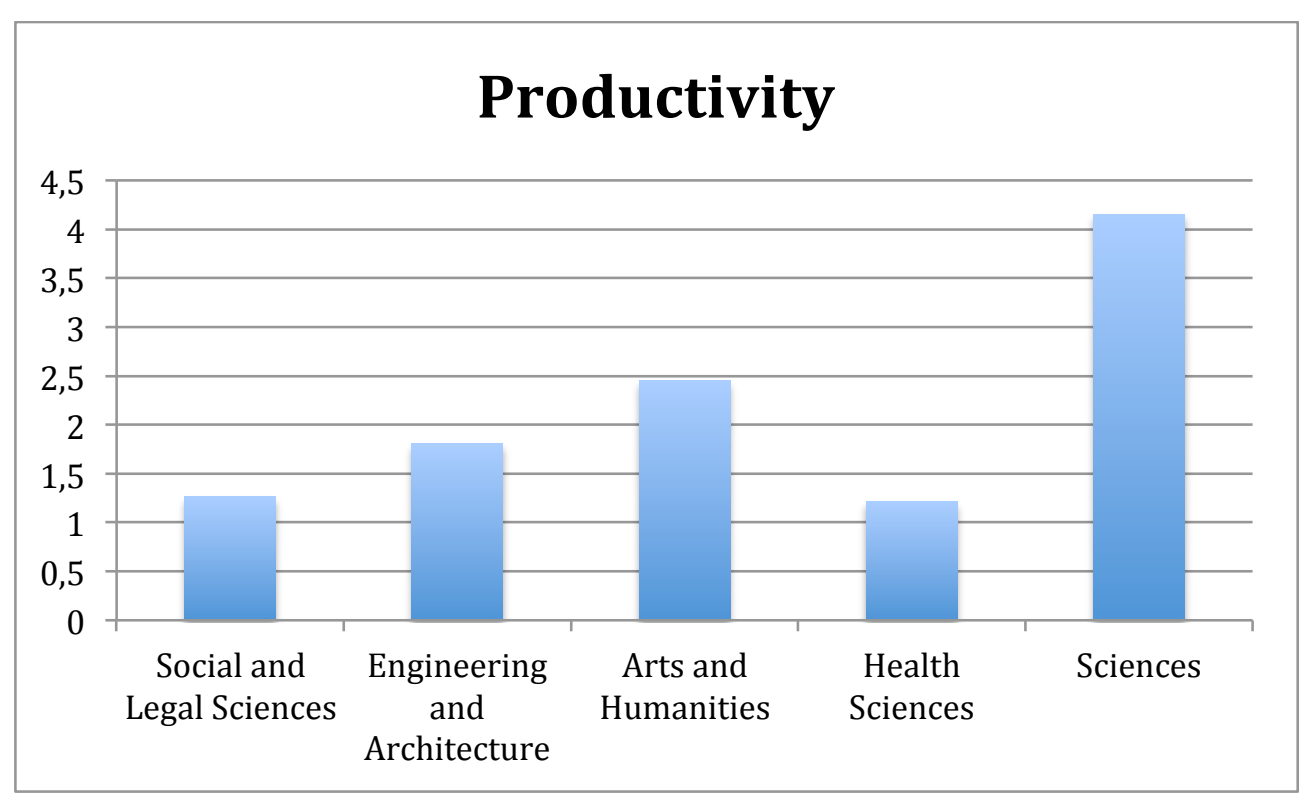

Figure 1. Productivity by areas of knowledge.

In the second of the instruments which the administration created and which is highly contradictory to us in view of the data it presents in relation to the PDI group and their research productivity, the treatment given to humanities in relation to sciences is confusing, when an official report is made on the social perception of science among citizens (such as the one produced each year by the Spanish Foundation for Science and Technology) (FECYT, 2018).

First, this report is entitled Social Perception of Science and Technology, with which we could assume a priori that in such a denomination of science, citizens understand that Humanities and Social Sciences are included. This, however, would be very risky. When we analyzed the content, we found no explicit reference to what is considered "science" and what its authors assume citizens to understand by "science." In addition, the report did not include an explanation of a category of science grouped under "technology."

Either good or bad, the report does nothing more than follow the general trend in all countries, prioritizing the promotion of STEM areas, a well-established field in Europe for decades (Pardo and Calvo, 2002) where the "Eurobarometers" began to be developed. However, the confusion and contradiction produced by this report increased when we saw what citizens were asked in relation to their topics of interest. For the authors of the report, (i.e., the administration), it seems that education, cinema, work and employment, and politics are social concerns different from those related to "science" and "technology," as if there was no research and studies in pedagogy, film analysis, sociology of work or political science. When analyzed in greater detail, only a specific relationship was established between "science" and "health" (FECYT, 2018: 259), in line with the generalization of the therapeutic discourse associated with therapeutic culture (Illouz, 2008) and closely related to the previously mentioned "MIT ideology." Additionally, in the same vein, FECYT is extremely interested in determining the perceived social utility of science and technology (FECYT, 2018: 107). In our opinion, this is one of the ultimate objectives of the report.

Around $60 \%$ of the people interviewed state agree with:

- Science and technology solving problems, but also creating them (63.9\%).

- Science and technology serving, above all, to solve problems (61.0\%). 
- Science and technology being the highest expression of prosperity in our society $(58.8 \%)$.

Thus, the question we ask ourselves is: where is science in the areas of Humanities and Social Sciences, as shown in this report? Is it that Humanities and Social Sciences do not solve problems, but instead create them? Do they not contribute to the prosperity of our society?

We are not saying that promoting scientific vocations and STEM disciplines among citizens is not necessary. Quite the contrary. However, in the first approach, we have only verified the following: because of this new ideology of progress and innovation, Humanities and Social Sciences seem far from institutional interests, and will be so until they are fully considered as "sciences." They are undoubtedly interesting for social issues and those affecting people's lives. However, it is unreasonable that the administration does not consider it necessary to understand the social perception of the scientific knowledge resulting from the activity of $45 \%$ of the university teaching staff belonging to these areas, and that they do not even value it as science. This paradox of the administration between university activity and scientific research leads us to our initial research question.

H1: What is the relevance of the knowledge generated from universities in the areas of Humanities and Social Sciences from the perspective of the administration?

\section{SINC news agency.}

The SINC news agency was created in 2008 with the main function of collecting and disseminating knowledge from a journalistic point of view, preferably in the form of "informative" content. The agency would, therefore, contribute toward the promotion of scientific culture, both directly to the citizens from its own digital platform, and by providing content and informational resources on social media. The data resulting from this first analysis of the contents distributed by SINC since its creation indicate that they are structured by thematic areas, as shown in Figure 3.

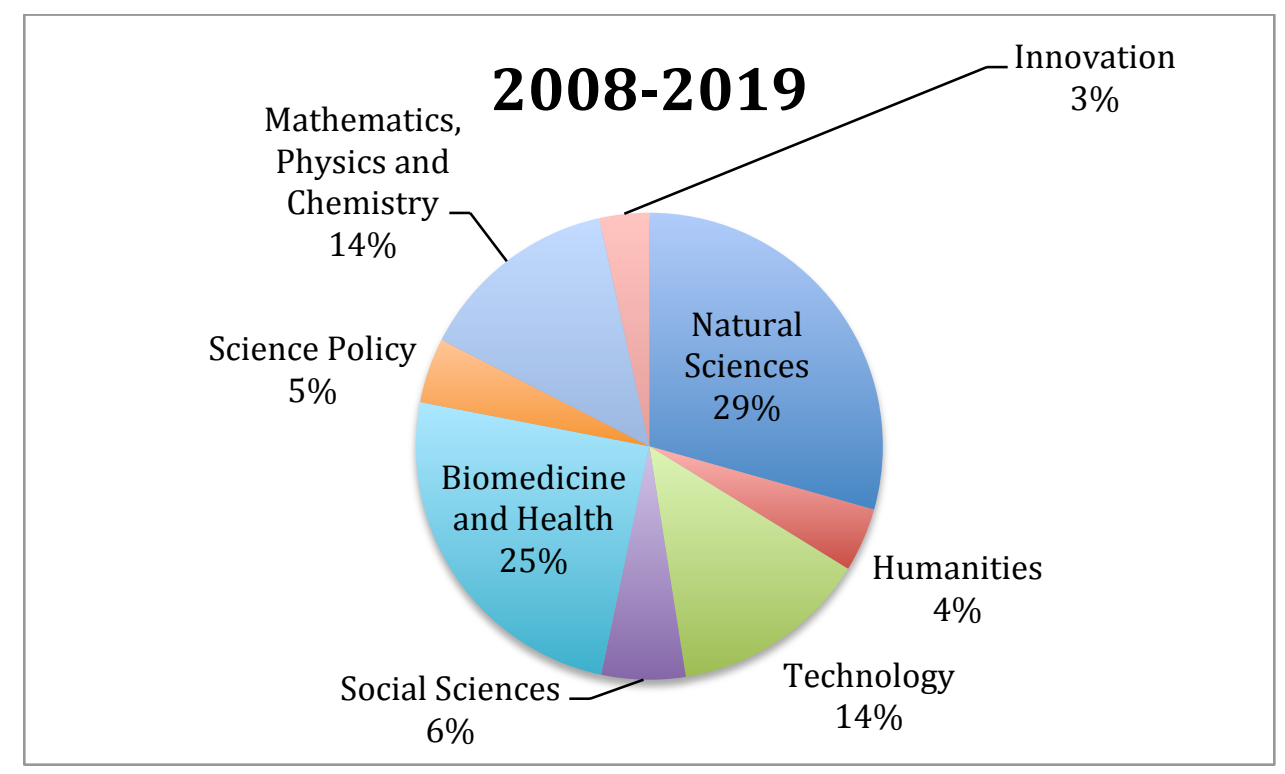

Figure 2. Content distribution by disciplines in SINC. 
We can observe two significant aspects of the SINC-FECYT institutional communication policy, as a reference for the ministerial activity in the social promotion of knowledge in Spain. First, ad hoc classification categories have been created that go beyond the areas of knowledge established by the administration to evaluate scientific activity. However, this is neither better nor worse, and far from being not criticized, since any specialist in library science and documentation or in any area of "humanities" knows the difficulties in establishing concepts and closed terminologies in the elaboration of the thesauri and in classifications. Second, following the general trend in the dissemination of scientific knowledge, the published content in the areas of Humanities and Social Sciences is significantly lower than those in the areas of Biomedicine and Health, and Natural Sciences. They are also lower than Mathematics, Physics and Chemistry. The content in Innovation is practically testimonial.

With the data obtained after this initial analysis of the contradictions, we can estimate the institutional care ratio of each of the large areas of knowledge. However, as we already stated, the different forms of classification by areas within the administration only allow an approximate assessment of some of them, which are the most significant, and those that we consider of interest for our investigation (Table 1).

\begin{tabular}{|l|r|r|r|r|}
\hline \multicolumn{1}{|c|}{ News } & Humanities & Social Sciences & Science & \multicolumn{2}{c|}{ Biomedicine and } \\
Health
\end{tabular}

Table 1. Institutional popularization ratio in SINC.

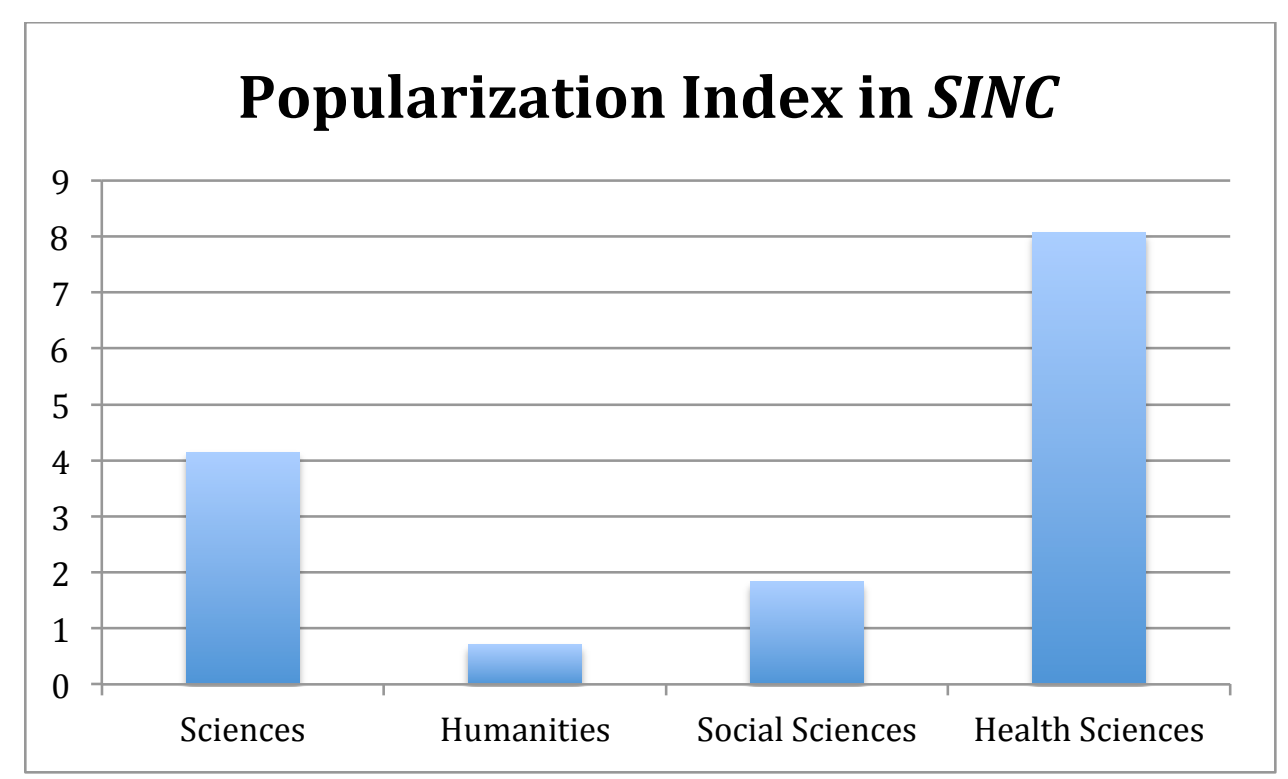


Figure 3. Popularization index by areas of knowledge.

After calculating the Popularization Index (Figure 4) (ip=News/Productivity, base 100), the significant differences in treatment received by the knowledge generated in the areas of Humanities (ip $=0.71)$ and Social Sciences $(i p=1.82)$ is evidenced and compared with Biomedicine and Health (ip $=8.06)$ and Sciences (ip $=4.15)$. In this, we have included those classified by SINC in the category of Natural Sciences, and Mathematics, Physics and Chemistry.

This is not surprising since most of the studies in this regard-with the differences expressed according to the methodology used-follow the general tendency in all countries towards promoting "scientific" areas of knowledge on social media, and the results of the previously mentioned analysis of the press in Spain (Groves et al., 2016: 699) show that 32\% of the total articles correspond to the areas of Biomedicine (19\%) and Public Health (13\%).

Based on this, at least from the quantitative point of view, we can draw the first conclusion: research in the Humanities area $(\mathrm{p}=2.45$; ip $=0.71)$ does not receive adequate attention and is not promoted by the SINC. On the other hand, research in Social Sciences is given a certain priority by the agency for public dissemination, which is slightly above the research productivity of the area $(\mathrm{p}=1.25$, ip $=1.82)$.

After verifying the initial contradictions and partially responding to the hypothesis raised from these preliminary data, in this research work, we carried out a detailed study of the Humanities and Social Sciences content classified in SINC. Complementary hypotheses to the main one (H1) in this research are then proposed:

H1a - SINC prioritizes "institutionally" the contents that allow resolving conflicts and facilitating progress.

$\mathrm{H} 1 \mathrm{~b}$ - The institutional treatment of the contents (H1a) prioritizes investigations that show results based on the concept of "scientific truth" and "objective data," avoiding the inherent uncertainty in any representation of knowledge (xxx, 2019)

Finally, as a conclusive hypothesis resulting from the previous ones, we propose that:

$\mathrm{H} 2$ - SINC-FECYT establishes a discursive strategy that promotes a model of scientific culture framed in neopositivist ideological currents that is based on techno-scientific progress.

\section{Research methodology.}

To validate our working hypotheses, we used a content analysis methodology based on linguistic pragmatics and the Speech Act theory, proposed by Austin and completed by Searle, which affect the performative character of language (Searle, 1969). From this theoretical perspective, we use the Frame Analysis methodology (Goffman, 1974) for our analysis, understanding that the framing process "essentially involves selection and salience" (Entman, 1993: 52).

To carry out our analysis, we adopted the proposals of Tankard (2001: 101), in relation to the different mechanisms used to identify the framing strategy of the informative content; we specifically analyzed titles, subtitles and lead. Likewise, we assumed the Gamson and Modigliani (1989) differentiation of framing devices to identify condensed information in 
relation to a certain topic in the form of metaphors, examples, phrases and keywords, and descriptions. Based on these proposals, we carried out an analysis strictly limited to written information. The analysis of visual content would require a specific investigation that is not in the objectives of this study.

We used a deductive-inductive strategy from the down-up methodological perspective proposed by the Grounded Theory (Glasser and Strauss, 1967) to determine the interpretive frames, which directly extracts the significant terms and phrases. From this, in accordance with the Frame Theory proposals, we group them into the categories proposed in the study's hypotheses.

To this end, first, by means of a deductive strategy, we established the contents in the disciplines under analysis. Second, we classified them inductively according to their "institutional newsworthiness" (H1a) from the ideological perspective of their usefulness for the "resolution" of "conflicts" and contributing to "progress" and in relation to their "scientificity" (H1b). This would be determined by the use of empirical methodology, often with the explicit "datafication" (Latour, 2010) of the informative contents and avoiding showing "uncertainty" in the research results.

Taking this methodological perspective as the main object of study and a starting point, we defined the content of the headlines of the textually informative content published by the SINC agency over the last two years (2018-2019) classified into the Humanities $(\mathrm{N}=81)$ and Social Sciences $(\mathrm{N}=156)$ labels. Complementarily, we also analyzed the disciplines corresponding to the most popular contents in all areas of knowledge among readers during 2015-2019 period.

To improve the precision of the study, we divided the research into two phases and selected a sample of Science content for comparison during the 2018-2019 period, and over a period of five years (2015-2019), as detailed below.

In the first phase of the research, we analyzed the disciplines corresponding to the most popular content among the readers of the SINC portal during the last five years (2015-2019). We compared them with a random sample of all those classified in the areas of Humanities $(\mathrm{N}=$ $245, \mathrm{n}=24)$ and Social Sciences $(\mathrm{N}=506, \mathrm{n}=51)$ throughout the same five-year period.

In the second phase, we carried out an analysis of the different devices used for framing the contents classified in the areas of Humanities and Social Sciences published between 20182019. Next, we compared them with a random sample of those published and classified during the same period in Natural Sciences $(\mathrm{N}=925, \mathrm{n}=93)$-which has one of the largest presence in SINC (29\% of the total published materials since its inception)-and in the area of Mathematics, Physics and Chemistry $(\mathrm{N}=413, \mathrm{n}=42)$, due to the common perception of its unambiguous definition of "science," and whose absolute presence in SINC publications since its inception is $14 \%$.

For comparative and complementary purposes, we compiled a random sample of Humanities and Social Sciences content from a total of 75 publications corresponding to the period 2015-2019 $(\mathrm{N}=751, \mathrm{n}=75$, confidence level $=95 \%$, margin of error and $=6.4 \%$ for $\mathrm{pq}=0.9$ and $\mathrm{e}=9.3 \%$ for $\mathrm{pq}=0.75$ ); and 135 publications on Natural Sciences and Mathematics, Physics and Chemistry corresponding to the period 2018-2019 $(\mathrm{N}=1338, \mathrm{n}=135$, confidence level $=95 \%$, margin of error $\mathrm{e}=4.8 \%$ for $\mathrm{pq}=0.9$ and $\mathrm{e}=6.9 \%$ for $\mathrm{pq}=0.75$ ).

This analysis methodology allows us to identify and classify the differences and similarities in each of the areas of knowledge under study and their specific framing strategies. In this manner, we respond to the research hypotheses raised in relation to SINC's treatment of research in Human and Social Sciences (H1a), their relationship with the predominant scientific 
trend (H1b), and the scientific culture model promoted by the Spanish public administration through SINC-FECYT (H2).

\section{Results of the investigation.}

It can be observed that the production of classified content has decreased in the fiveyear periods analyzed in all areas, even though this decrease is especially significant in Innovation (-74.6\%) and Scientific Policy (-64.4\%); it is less pronounced in Technology ($2.1 \%)$ and Biomedicine and Health (-44.8\%). Natural Sciences (-51.7\%) and Mathematics, Physics, and Chemistry (-54.9\%) were reduced by around half, and their already scarce presence compared to the rest of Human Sciences (-61\%) and Social Sciences (-62.5\%) becomes much more pronounced (Figure 4).

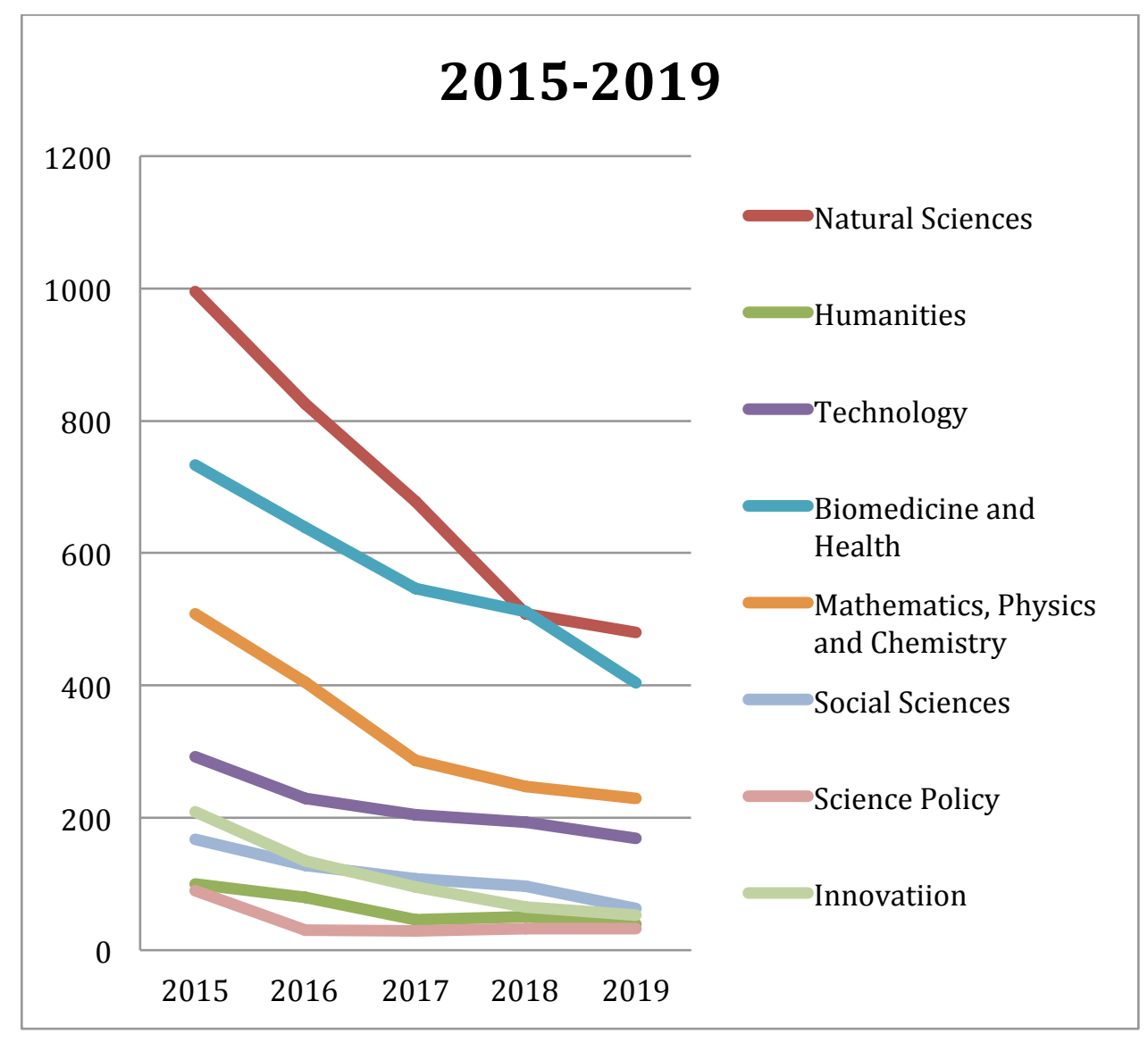

Figure 4. Evolution of contents by SINC areas (2015-2019).

In a more specific comparative analysis by disciplines, we observe that the presence of Sociology, Psychology and History is predominant when compared to the rest of the areas. The most significant aspect, however, is the disappearance of Philosophy, which went from representing $7.4 \%$ in the $2015-2019$ period, to only having a presence of $0.42 \%$ in the 2018 2019 period (Figure 8 and 9). 


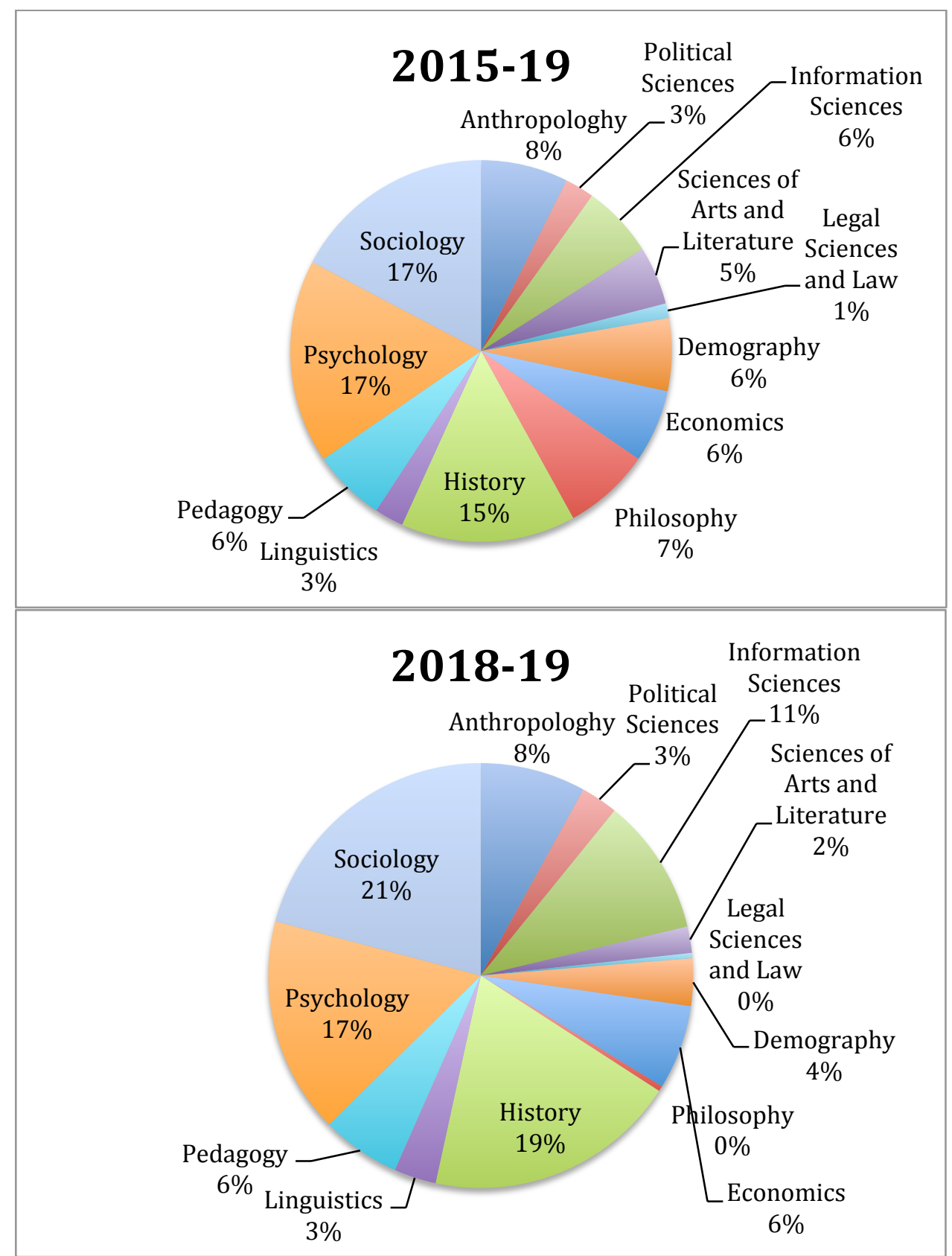

Figures 5 and 6. SINC Content distribution by areas (2015-2019 and 2018-2019).

The comparative analysis of the contents in the different disciplines belonging to the "scientific" and "humanistic" areas present in SINC, over the last two years, confirms the significant attention that some of them receive. In science, Physics and Life Sciences stand out more prominently than any other discipline, and in the humanities, Sociology, History and Psychology are more prominent (Figure 7). 


\section{8-2019}

Demography

Legal Sciences and Law Sciences of Arts and Literature Life Sciences

Earth and Space Sciences Information Sciences Agricultural Sciences

Political Sciences Astronomy and Astrophysics Anthropologhy $\begin{array}{llllllllll}0 & 10 & 20 & 30 & 40 & 50 & 60 & 70 & 80 & 90\end{array}$

Figure 7. Content distribution by SINC disciplines (2018-2019).

Regarding the interest that different content aroused among readers in the five-year period analyzed, the most popular disciplines were those integrated in Health and Biomedicine (44.64\%), followed by Natural Sciences (32.14\%), Mathematics, Physics and Chemistry $(10.71 \%)$, and Social Sciences (10.71\%). Humanities (1.78\%) arouse little interest, and in the period, there is only one article among the most read, specifically a 2015 interview with the philosopher of science Daniel Dennett, wherein he questions the usefulness of religion for moral progress (Jar, 2015) (Figure 8). 


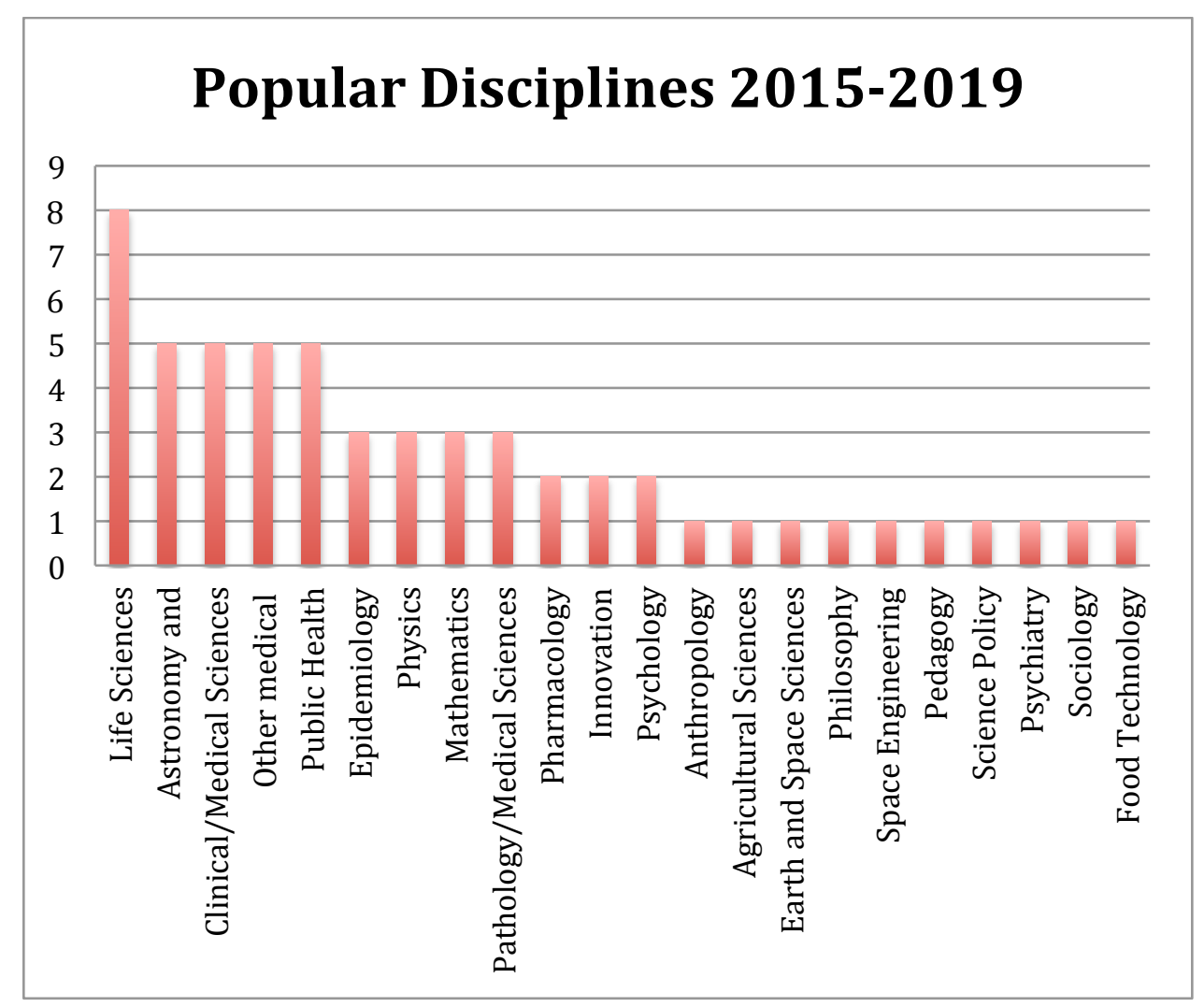

Figure 8. Most popular disciplines among SINC readers (2015-2019).

If we return to the initial data, we can observe that research in the areas of Biomedicine and Health is much more interesting from an institutional point of view (ip $=8.06)$ and for the readers $(\mathrm{il}=20.52)$ than any other, despite its low productivity $(\mathrm{p}=1.21)$ with respect to, for example, scientific research $(\mathrm{p}=4.15$; ip $=4.15$; il $=5.7)$. On the contrary, Humanities are of very little interest for the institution (ip $=0.71)$ and for the readers (il $=0.40)$, despite their high research productivity $(\mathrm{p}=2.45)$ (Table 2$)$.

\begin{tabular}{|c|r|r|r|r|}
\hline & Humanities & Social Sciences & Sciences & Biomedicine and Health \\
\hline Number of popular & & & 2 & \\
news articles 2015-19 & 1 & 6 & 4 & 25 \\
\hline PDI Productivity (p) & 2.4 & & 4 & 1.21 \\
\hline Institutional & 5 & 1.26 & .15 & 8.06 \\
\hline Popularization (ip) & 0.7 & & 4 & \\
Reader & 1 & 1.82 & .15 & 20.52 \\
Interest/Productivity (ir) & 0.4 & & 5 & \\
Institutional & 0 & 4.74 & .77 & 2.54 \\
Effectiveness (ie=ir/ip) & 6 & & 1 & .39 \\
\hline
\end{tabular}

Table 2. Ratios of popularization, reader interest, and institutional effectiveness.

The communication strategy in the promotion of certain areas was very effective in the case of Social Sciences (ie $=2.59$ ) and in Biomedicine and Health (ie = 2.54). It is still optimal in Sciences (ie $=1.39$ ), while in Humanities, it is well below par (ie $=0.56$ ). 


\section{Interpretive frameworks}

Regarding the results of the comparative analysis of the interpretive frameworks with which the contents in Humanities and Social Sciences are presented to the readers in the fiveyear period sample, some interesting results can be observed, as shown in Table 3.

\begin{tabular}{|l|l|l|l|}
\hline \multirow{3}{*}{ H1a } & $\begin{array}{l}\text { 2015-2019 } \\
\text { \% of the total }\end{array}$ & Social Sciences & Humanities \\
\hline \multirow{3}{*}{ Conflict } & Resolution & 33.33 & 4.16 \\
\cline { 2 - 5 } & Progressiveness & 23.52 & 12.50 \\
\cline { 2 - 5 } & Datafication & 11.76 & 12.50 \\
\cline { 2 - 5 } & Certainty & 29.41 & 20.83 \\
\cline { 2 - 5 } & & 23.52 & 58.33 \\
\hline
\end{tabular}

Table 3. Humanities and Social Sciences interpretive frameworks (2015-2019).

First, from the point of view of their "institutional newsworthiness" (H1a), the contents are selected based on their "conflictivity" to a greater extent in Social Sciences $(33.33 \%)$ than in Humanities $(4.16 \%)$, as well as in relation to their ability to provide "solutions" $(23.52 \%$ and $12.50 \%$, respectively).

Although both areas of study timidly contribute to "progress" $(11.76 \%$ and $12.50 \%$ of the contents of the period in each discipline, respectively), in Social Sciences, a more "scientistic" framework of interpretation (H1b) based on "data" (29.41\%) is provided. Explicitly, in the content of both disciplines, an attempt is made to provide different degrees of "certainty," with more interest in Humanities (58.33\%). Nevertheless, in Social Sciences, expressions related to the results, such as "relevant and reliable," "put in evidence," "contrasted truths", and "scientific evidence" are used. However, in Humanities, they are more cautious with the objectivity of their conclusions and expressions, such as "it is pointed out," "it contributes to the knowledge," "some unknowns have been resolved" and even "you will end up with more doubts" are used.

In the more specific and comparative analysis of the total number of articles published in Humanities and Social Sciences with a sample of those understood as "science" corresponding to the last two years (2018-2019), the results can be qualified, and the specific interpretation framework proposed by SINC for the Humanities and Social Sciences can be established with more precision (Table 4).

\begin{tabular}{|l|l|r|r|l|l|}
\hline & $\begin{array}{l}2018-2019 \\
\% \text { of the total }\end{array}$ & Social Sciences & Humanities & $\begin{array}{l}\text { Natural } \\
\text { Sciences }\end{array}$ & $\begin{array}{l}\text { Mathematics, } \\
\text { Physics and } \\
\text { Chemistry }\end{array}$ \\
\hline & Conflict & 21.51 & 15.51 & 28.20 & 12.5 \\
\hline
\end{tabular}




\begin{tabular}{|l|l|r|r|r|r|}
\hline H1a & Resolution & 33.33 & 5.17 & 12.65 & 50 \\
\cline { 2 - 6 } & Progressiveness & 9.49 & 12.50 & 8.62 & 40.62 \\
\hline \multirow{2}{*}{ H1b } & Datafication & 34.61 & 41.37 & 39.74 & 34.73 \\
\cline { 2 - 6 } & Certainty & 18.98 & 18.98 & 15.51 & 12.50 \\
\cline { 2 - 6 } & Uncertainty & 10.12 & 25.86 & 25.64 & 34.37 \\
\hline
\end{tabular}

Table 4. Compared interpretive frameworks (2018-2019).

As can be seen, the contents of the Natural Sciences areas are mostly presented to the readers from the perspective of their "institutional newsworthiness" (H1a) based on their "conflictivity" (28.20\%), which in this case is related to ecological issues (climate change, conservationism) such as "floods caused by climate change," "the extinction of brown bears" or the spread of "pests." Conflicts in Social Sciences (21.5\%) refer to economic and social inequalities: the "labor market," "evictions" or "immigration" or "political corruption." In Humanities, they refer to ideological issues such as "the rise of the right wing," or to gender such as the "sexualization of sports" (15.51\%). The contents of "gender" are significant in both areas, especially in Social Sciences, where they represent $24.68 \%$ of the total.

In relation to the "resolution" capacity of the research carried out in each area, more solutions are provided in Mathematics, Physics and Chemistry contents $(50 \%)$. The solutions are usually of a technological nature such as "increasing brightness and duration of OLED lamps" and, although they sometimes have applications in other areas, such as "continuously releasing a drug" or "the use of air as an inexpensive and environmentally friendly antioxidant," they are preferably intended for the advancement of research. Thus, in this area, "progressiveness" (40.62\%) is understood as a scientific advance, for example to "allow viewing and downloading astronomical data" or "channeling light."

In comparative terms, research from the Natural Sciences is shown as more descriptive and less grounded in continuous scientific advance, similar to what occurs in Humanities $(12.50 \%)$ and Social Sciences $(9.49 \%)$. Although in Humanities, it is presented in a more abstract way, for example to "inspire," "innovate" or for its "positive effects," in Social Sciences, it refers more to its contribution "to improve people's lives," "to facilitate the day to day," and toward "development" and "well-being."

Regarding the presentation of the SINC contents according to their "scientificity" (H1b), similar figures are observed in all areas regarding the institutional interest in showing the results with data that support their "objectivity and scientific truth" in the commented terms of the prevailing neopositivist ideology currently in research.

However, a more detailed analysis for this two-year period reveals some interesting results in this regard (Table 5).

\begin{tabular}{|l|l|r|r|l|l|}
\hline & $\begin{array}{l}2018-2019 \\
\% \text { of the total }\end{array}$ & Social Sciences & Humanities & $\begin{array}{l}\text { Natural } \\
\text { Sciences }\end{array}$ & $\begin{array}{l}\text { Mathematics, } \\
\text { Physics and } \\
\text { Chemistry }\end{array}$ \\
\hline H1b & Datafication & 34.61 & 41.37 & 39.74 & 34.73 \\
\hline
\end{tabular}




\begin{tabular}{|l|lcccr|}
\hline & Certainty & 18.98 & 18.98 & 15.51 & 12.50 \\
\cline { 2 - 6 } & Uncertainty & 10.12 & 25.86 & 25.64 & 34.37 \\
\cline { 2 - 5 } & Ratio C/I & 1.86 & 0.73 & 0.60 & 0.36 \\
\hline
\end{tabular}

Table 5. Certainty and datafication comparative ratios (2018-2019).

The contents in Mathematics, Physics and Chemistry $(r=0.36)$ and Natural Sciences $(r$ $=0.60)$ are, paradoxically, the ones that show greater caution in presenting their conclusions as absolute truths, and terms denoting uncertainty such as "would reinforce the hypothesis," "would indicate," "appears to be involved," and "the results suggest" are frequently used. However, the contents in Social Sciences are are presented with more determination from SINC as "objective" knowledge $(\mathrm{r}=1.86)$, with terms such as "there is evidence," "a direct correlation," "the experts have found" and the like; and to a much lesser extent, those in Humanities (0.73), wherein terms such as "suggests that," "it is probable that," "the data help" are used more frequently, similar to how the contents of the so-called "sciences" are presented.

\section{Conclusions.}

First, as determined in our research in absolute figures, almost $50 \%$ of the total PDI assigned to Humanities and the total accumulated research six-year terms are of no interest to the SINC readers, a figure that has to be clarified, given that the administration itself does not promote the content according to the productivity of the group (ip $=0.71)$.

In comparative terms, the results show that SINC intensively promotes Biomedicine and Health (ip = 8.06) and Sciences (ip = 4.15) content. However, those that are of greatest interest to readers despite the modest institutional attention they receive (ip $=1.82$ ) are in Social Sciences $(\mathrm{ie}=2.59)$.

Regarding the presence of content from different areas and SINC's interest in promoting them, we can answer the general hypothesis of this research (H1) and establish the interpretive framework that is institutionally proposed to the readers by SINC.

F1: The journalistic work must prioritize the contents in Biomedicine and Health, which are also the most popular among readers, and those in "sciences" must be promoted, among which Social Sciences must be included. Their usefulness must be valued because they are popular contents among the readers. Humanities do not require attention because, despite being a very productive area, its results are not so "scientific," and arouse little interest among the readers.

Based on this, we can establish the preferential interpretation framework that is proposed to readers in the contents of SINC from the perspective of "institutional newsworthiness" (H1a) and "scientificity" (H1b) of the research on the areas of Humanities and Social Sciences.

F1-CS: The content of Social Sciences is presented by promoting an interpretive reading framework that values their scientificity, and in relation to their degree of conflict and ability to provide solutions with reliable data, while their results contribute to well-being and development. 
F1-H: The content of Humanities, however, are presented from a less scientific perspective; they deal with less conflictive issues and are of little use due to their limited capacity to provide solutions, beyond an abstract contribution to progress.

F1-CS+H/Sciences: In relation to the so-called sciences, the content in Social Sciences and Humanities also need to show data to validate their research results. However, SINC makes a special effort to promote the "scientific" status of the contents related to the Social Sciences to equate it with the rest of the "sciences."

Finally, without nuances, we can confirm our conclusive hypothesis (H2): SINC-FECYT has established a discursive strategy that promotes a utilitarian scientific culture model framed in neo-positivist ideological currents that is based on the techno-scientific progress and the social utility of research.

\section{BIBLIOGRAPHY}

Bentley, P. y Kyvik, S. (2011). Academic staff and public communication: a survey of popular science publishing across 13 countries. Public Understanding of Science, 20 (1), pp. 48-63. https://doi.org/10.1177/0963662510384461

Besley, J., Dudo, A., Yan, S. (2018). The National Science Foundation's science and technology survey and support for science funding, 2006-2014. Public Understanding of Science, 27 (1), pp. 94-109. https://doi.org/10.1177/0963662516649803

Bueno, D., Casanovas, J., Garcés, M., Vilalta, J. (2019). Higher Education in the World 7. Humanities and Higher Education: Synergies between Science, Technology and Humanities. En: http://www.guninetwork.org

Bush, V. (1945). Science the Endless Frontier. En: https://www.nsf.gov/od/lpa/nsf50/vbush1945.htm

Davidson-Harden, A. (2013). What is Social Sciences and Humanities Research 'Worth'? Neoliberalism and the Framing of Social Sciences and Humanities Work in Canada. Policy Futures in Education, 11 (4), pp. 387-400. https://doi.org/10.2304/pfie.2013.11.4.387

Entman, R. (1993). Framing: Toward clarification of a fractured paradigm. Journal of Communication, v. 43, n. 4, pp. 51-58. https://doi.org/10.1111/j.1460-2466.1993.tb01304.x

FECYT (2018). IX EPSCYT 2018. Informe de resultados. Fundacion Española de Ciencia y Tecnologia. En: https://icono.fecyt.es/informes-y-publicaciones/percepcion-social-dela-ciencia-y-la-tecnologia-en-espana

Gamson, W. y Modigliani, A. (1989). Media Discourse and Public Opinion on Nuclear Power: A Constructionist Approach. American Journal of Sociology, 95 (1), pp. 1-37. https://doi.org/10.1086/229213

Glasser, B. y Strauss, A. (1967). The discovery of grounded theory strategies for qualitative research. Chicago: Aldine Publications. ISBN: ISBN 0-202-30260-1

Goffman, E. (1974). Frame Analysis: An Essay on the Organization of Experience. Cambridge, MA, US: Harvard University Press. ISBN: 9780930350918

Griffin, G. (2007). Future Priorities of the Humanities in Europe: What Have the Humanities to Offer?. Arts \& Humanities in Higher Education, 6 (1), pp. 123-127. https://doi.org/10.1177/1474022207072234

Grove, J. (2015). Social sciences and humanities faculties "to close" in Japan after ministerial intervention. TimesHigherEducation, 14 septiembre. https://www.timeshighereducation.com/news/social-sciences-and-humanities-faculties-close- 
japan-after-ministerial-intervention

Groves, T., Figuerola, C., Quintanilla, M. A. (2016). Ten years of science news: A longitudinal analysis of scientific culture in the Spanish digital press. Public Understanding of Science, 25 (6), pp. 691-705. https://doi.org/10.1177/0963662515576864

Gustafson, A. y Rice, R. (2019). The Effects of Uncertainty Frames in Three Science Communication Topics. Science Communication, 41 (6), pp. 679-706. https://doi.org/10.1177/1075547019870811

Huber, B., Wetzstein, I., Aichberger, I. (2019). Societal problem solver or deficient discipline? The debate about social science in the online public sphere. Journal of Science Communication, 18 (2), pp. 1-21. https://doi.org/10.22323/2.18020204

Illouz, E. (2008). Saving the modern soul : therapy, emotions, and the culture of selfhelp. University of California Press. ISBN: 9780520253735

Jar, N. (2015). La religión no es el motor de la moral sino el freno que ha ralentizado su desarrollo. SINC, 24 julio. https://www.agenciasinc.es/Entrevistas/La-religion-no-es-el-motorde-la-moral-sino-el-freno-que-ha-ralentizado-su-desarrollo

Knudsen, S. (2017). Thinking inside the frame: A framing analysis of the humanities in Danish print news media. Public Understanding of Science, 26 (8), pp. 908-924.

https://doi.org/10.1177/0963662517693452

Landström, C., Hauxwell-Baldwin, R., Lorenzoni, I., Rogers-Hayden, T. (2015). The (Mis)understanding of Scientific Uncertainty? How Experts View Policy-Makers, the Media and Publics. Science as Culture, 24 (3), pp. 276-298.

https://doi.org/10.1080/09505431.2014.992333

Latour, B. (2010). Tarde's idea of quantification. En: Candea, M. The Social After Gabriel Tarde: Debates and Assessments, pp. 145-162. ISBN: 9781135998707

Lindsay, J., Boghossian, P., Pluckrose, H. (2018). Academic Grievance Studies and the Corruption of Scholarship. https://areomagazine.com/2018/10/02/academic-grievance-studiesand-the-corruption-of-scholarship/

Educación.

Ministerio de Educación. Secretaría General de Universidades (2019). Estadísticas de http://estadisticas.mecd.gob.es/EducaJaxiPx/Datos.htm?path=/Universitaria/Personal/Curso 2017-2018/PDI//10/\&file=PDI0107.px\&type $=$ pcaxis

Morozov, E. (2013). To save everything, click here: Technology, Solutionism, and the Urge to Fix Problems that Don't Exist. Allen Lane. ISBN: 9781846145483

Olmos-Peña, J., Benneworth, P., Castro-Martínez, E., Olmos-Peñuela, J. (2015). Are sciences essential and humanities elective? Disentangling competing claims for humanities' research public value. Arts \& Humanities in Higher Education, 14 (1), pp. 61-78. https://doi.org/10.1177/1474022214534081

Pardo, R. y Calvo, F. (2002). Attitudes toward science among the European public: a methodological analysis. Public Understanding of Science, 11 (2), pp. 155-195. https://doi.org/10.1088/0963-6625/11/2/305

Pestre, D. (2008). Challenges for the Democratic Management of Technoscience: Governance, Participation and the Political Today. Science as Culture, 17 (2), pp. 101-119. https://doi.org/10.1080/09505430802062869

Quintanilla, M. A. (2015). Algunos retos filosóficos de la política científica. Revista CTS, 10 (28), pp. 89-104.

http://www.revistacts.net/files/Volumen_10_Numero_28/FINAL/FINAL\%20PORTUGUES/06 Quintanilla.pdf 
Rivero-Franyutti, A. (2013). ¿Qué son hoy las humanidades y cuál ha sido su valor en la universidad?. Revista de Educación Superior, XLII (3), pp. 81-100.

http://publicaciones.anuies.mx/pdfs/revista/Revista167_S2A1ES.pdf

Rodríguez-Serrano, A.; Gil-Soldevilla, S. (2018). Investigar en la era neoliberal : visiones críticas sobre la investigación en comunicación en España. Barcelona: Universitat Autònoma de Barcelona, Servei de Publicacions. ISBN: 9788449080401

Schäfer, M. (2012). Taking stock: A meta-analysis of studies on the media's coverage of science. Public Understanding of Science, 21 (6), pp. 650-663.

https://doi.org/10.1177/0963662510387559

Schäfer, M., Metag, J., Feustle, J., Herzog, Livia (2016). Selling science 2.0: What scientific projects receive crowdfunding online?. Public Understanding of Science, 27 (5), pp. 496-514. https://doi.org/10.1177/0963662516668771

Searle, J. (1969). Speech acts: An essay in the philosophy of language. Cambridge University Press. ISBN: 9780521096263

Snow, CP (2000). Las dos culturas. Nueva Visión. ISBN: 978950602401 61970749

Sokal, A. y Bricmont, J. (1998). Intellectual Impostures. Profile Books. ISBN: 97818

Šuljok, A. y Vuković, M. B. (2013). How the Croatian daily press presents science news. Science and Technology Studies, 26 (1), pp. 92-112. http://idiprints.knjiznica.idi.hr/53/

Summ, A. y Volpers, A. M. (2016). What's science? Where's science? Science journalism in German print media. Public Understanding of Science, 25 (7), pp. 775-790. https://doi.org/10.1177/0963662515583419

Tankard, J. (2001). The Empirical Approach to the Study of Media Framing. En: Reese, S., Gandy, O., Grant, A. (eds.). Framing Public Life Perspectives on Media and Our Understanding of the Social World, pp. 95-106. ISBN: 9780805849264.

Van Dijck, J. (2003). After the "Two Cultures". Toward a "(Multi)cultural" Practice of Science Communication. Science Communication, 25 (2), pp. 177-190.

https://doi.org/10.1177/1075547003259540

Vestergård, G. y Nielsen, K. (2016). Science news in a closed and an open media market: A comparative content analysis of print and online science news in Denmark and the United Kingdom. European Journal of Communication, 31 (6), pp. 661-677.

https://doi.org/10.1177/0267323116674110 